\title{
Práticas curriculares matemáticas em uma escola da zona rural do Ceará: padronizações, relações de cumplicidade e resistências no ensino de pessoas jovens, adultas e idosas ${ }^{1}$
}

\author{
Francisco Josimar Ricardo Xavier² \\ Adriano Vargas Freitas ${ }^{3}$
}

\section{Resumo}

Este artigo discute sobre padronização, relações de cumplicidade e movimentos de resistências percebidas nas práticas curriculares matemáticas de docentes que lecionam para jovens, adultos e idosos, em uma escola pública municipal da zona rural do Ceará. Para isso, foram utilizadas análises das narrativas de duas professoras e de acompanhamentos realizados em suas turmas, durante o primeiro semestre de 2018 . Os resultados sinalizam que as docentes constroem estratégias didáticas direcionando as aulas e conteúdos matemáticos para a valorização dos saberes dos estudantes, em detrimento das padronizações propostas pelo sistema municipal de ensino. Palavras-chave: Educação de Pessoas Jovens, Adultas e Idosas; Matemática; Práticas Curriculares.

Mathematical curricular practices in a school in rural Ceará: standards, complicity relationships and resistance in the teaching of young, adult and elderly people

\section{Abstract}

This article is about standardization, complicity relationships and resistance movements perceived in mathematical curriculum practices. These practices are from teachers who teach young people, adults and the elderly, in a municipal public school in rural Ceará. We analyzed the narratives of two teachers and followed their classes, during the first semester of 2018. The results indicate that the teachers build their didactic strategies, directing the classes and the mathematical contents for the valorization of the students' knowledge. They do not follow the standards proposed by the municipal education system.

Keywords: Education of Young, Adult and Elderly People; Mathematics; Curricular Practices.

\section{Considerações iniciais}

A educação voltada para pessoas jovens, adultas e idosas enfrenta, historicamente, um conjunto de dilemas teórico-práticos que se apresentam como privilegiados ao esforço de reflexão e debate. Entre estes, destacamos as influências entre as práticas pedagógicas matemáticas dos professores e os saberes que os estudantes apresentam de suas experiências cotidianas.

\footnotetext{
${ }^{1}$ Este artigo trata de resultados da pesquisa "A influência de práticas pedagógicas matemáticas na EJA sobre a permanência de estudantes da zona rural de Sobral", financiada pela Coordenação de Aperfeiçoamento de Pessoal de Ensino Superior (CAPES).

2 Universidade Federal Fluminense, Niterói, josimar_xavier@id.uff.br

${ }^{3}$ Universidade Federal Fluminense, Niterói, adrianovargas@id.uff.br
} 
Em uma leitura geral, estas influências, construídas no espaço escolar em torno da Matemática, podem ser entendidas como um desafio ao ensino dos professores que lecionam a referida disciplina. Compreendemos que este desafio se intensifica quando a escola é localizada na zona rural, tendo em vista que nestas ainda predominam propostas curriculares que não estão direcionadas às especificidades dos estudantes desta localidade, e, em geral, foram elaboradas para diferentes modalidades de ensino, tais como, a educação infantil.

Não queremos, com isso, afirmar que uma possível proposta curricular de Matemática voltada às escolas da zona rural, resolveria este desafio. Mas que, se nesta proposta fosse considerado um ensino que reconhecesse e respeitasse as especificidades e culturas dos sujeitos moradores dessa área geográfica, ela poderia ser um caminho à redução das desigualdades sociais.

Reconhecemos que são muitos os fatores que incidem sobre "o quê ensinar", e o "como ensinar" os saberes escolares aos estudantes. Muitas vezes a avaliação destes saberes é reduzida a resultados de testes de pequena ou larga escala, empregando à aprendizagem um sentido de "progresso acadêmico em um número restrito de áreas curriculares" (BIESTA, 2012, p.814). Nas turmas de Educação de Jovens e Adultos (EJA) que contemplam jovens, adultos e idosos, não tem sido diferente.

Mas que rumos podemos trilhar, para encaminhar, nos espaços escolares, uma aprendizagem que considere mais as culturas, as vivências e experiências dos jovens, adultos e idosos estudantes? Ousamos responder esta indagação informando que, no que tange ao ensino e aprendizagem dos saberes matemáticos, os professores construírem estratégias didáticas mais próximas das realidades dos estudantes seria uma possibilidade.

Elaboramos esta resposta baseados em nossa pesquisa cujo foco foi compreender as influências das práticas curriculares matemáticas de professores da EJA sobre a permanência dos estudantes jovens, adultos e idosos em uma escola da zona rural do Ceará (XAVIER, 2019). Dentre os resultados, a narrativa das docentes que foram acompanhadas e entrevistadas, nos possibilitou entender que elas constroem práticas curriculares que, em parte, se distanciam das

\footnotetext{
${ }^{4}$ Entendemos Educação de Jovens e Adultos (EJA) como a modalidade da Educação Básica que, dentre outras características, contempla a heterogeneidade de turmas com jovens, adultos e idosos como estudantes, buscando oferecer-Ihes um ensino específico às suas realidades (BRASIL, 2000).
}

Periódico Horizontes - USF - Itatiba, SP - Brasil - e020043 
padronizações propostas pelo sistema de ensino em que elas estão inseridas.

Entendemos este distanciamento como positivo, no sentido de que as docentes, ao elaborarem suas aulas com propostas pedagógicas próprias, estariam mais próximas das realidades dos estudantes. Isso sinaliza que elas reconhecem a pluralidade cultural e as especificidades das suas turmas, e encaminham suas práticas em um movimento de resistência às padronizações que lhes são propostas.

Partindo dessas premissas, objetivamos com este artigo, discutir as relações entre padronização, relações de cumplicidade e movimentos de resistências, percebidas nas práticas curriculares matemáticas de docentes que lecionam para jovens, adultos e idosos, em uma escola pública municipal de Sobral, cidade do interior do Estado do Ceará. Para isso, nos detemos em compreender os sentidos de currículos enunciados nas narrativas das docentes para, então, nos debruçarmos sobre como elas constroem suas práticas em sala de aula.

Enfatizamos que, ao trazer a especificidade de um estudo com lócus de pesquisa no Estado do Ceará, estamos contribuindo para a inclusão de parte da Região Nordeste nas discussões sobre currículos na EJA, pois, segundo Freitas (2013), estas têm se concentrado nas Regiões Sul e Sudeste do Brasil. Quando as professoras são apresentadas como participantes ativas da construção de currículos, alocamos nosso estudo entre os poucos do campo curricular da Educação Matemática na EJA que analisa as distâncias, ou diferenças e adaptações, ocorridas entre os currículos escolares prescritos e os efetivados nas salas de aulas (FREITAS, 2013).

O artigo é composto das seguintes seções: uma primeira, intitulada "A polissemia de currículos", em que destacamos nossos referenciais teóricos; em "O percurso da pesquisa", explicitamos os aspectos metodológicos do estudo, o perfil das professoras e das turmas de EJA acompanhadas. Na seção, "As práticas curriculares matemáticas", apontamos os resultados, lançando "Um olhar sobre os sentidos de currículos nas narrativas das docentes" e "Um olhar sobre as vivências matemáticas em sala de aula". Por fim, elaboramos as "Considerações finais".

\section{A polissemia de currículos}

Autores do campo curricular sinalizam que o termo "currículo" teve sua primeira aparição ligada às atividades educacionais na Universidade de Glasgow, na Inglaterra, 
aproximadamente no século XVII (SACRISTÁN, 2000; GOODSON, 2007; LOPES; MACEDO, 2011). Apontam eles que, desde então, o referido termo tem sido apresentado sob variados entendimentos, sendo o mais comum, estar relacionado à organização dos espaços escolares, às disciplinas e conteúdos a serem abordados nestas.

Decorre de Sacristán (2000) o apontamento de que o currículo traz representações simbólicas formalizadas, algumas entendidas diretamente, outras subentendidas, com que os sistemas de ensino buscam padronizar as práticas pedagógicas dos professores, os modos de estes construírem suas ações docentes em sala de aula. Para o referido autor, os professores, com suas resistências, são os agentes que se opõem aos modelos impostos, estando a frente com suas práticas e os saberes de suas vivências.

Entendemos, com isso, que o currículo não se finda em um texto escrito, mas vai sendo construído conforme os diálogos, as ações docentes, as vivências dos estudantes em sala de aula, e os princípios que norteiam o ensinar e o aprender no espaço escolar. Esta construção é sinalizada por Sacristán (2013, p.27) como uma "perspectiva processual e descentralizadora do currículo que propõe uma visão deste como algo que ocorre desde ser um plano até se converter em práticas pedagógicas". Estão, portanto, estas práticas envolvidas em sala de aula e com os contextos dos saberes dos estudantes e professores, formando o currículo.

Ao estudar a construção das disciplinas escolares, Goodson (2007) destaca haver místicas importantes sobre o currículo e o controle deste. Uma delas é de que, enquanto prescrição das ações docentes, há o entendimento de que "a especialização e o controle - do currículo - são inerentes ao governo central, às burocracias educacionais e à comunidade universitária" (GOODSON, 2007, p.242). Desde que, o que é prescrito como orientação, não interfira na vida dos professores, pode coexistir relações de cumplicidades entre prescrições e práticas pedagógicas. E, portanto, estando ambas as partes satisfeitas, ninguém desvela a mística desse controle curricular.

Em outro momento, Goodson (2015) discute, em especial, a vida e a voz dos professores, destacando as influências das reformas e reestruturações educacionais de alguns países sobre a ação docente, as histórias de vida e as biografias destes sujeitos. Sinaliza o referido autor que, em meio às transformações educacionais e curriculares, "o professor afirma-se como uma peçachave nesse sistema, embora sejam salientados os aspectos técnicos da sua profissão, em vez de 
ser dado destaque à sua biografia profissional" (GOODSON, 2015, p.63).

O estudo de Goodson (2015) aponta haver uma carência de destaque sobre o professor, no sentido de compreender que, para além de um profissional, ele é um sujeito que possui história de vida, e que esta é afetada quando se propõem reestruturações curriculares. Concordamos com o autor neste ponto. Contanto, consideramos que tais reestruturações incidem também, e diretamente, na vida dos estudantes. Além disso, entendemos que professores e estudantes, não são apenas agentes passivos dessas mudanças curriculares e que, por apresentarem narrativas de vidas específicas, é que pode haver movimentos de resistências, muitas vezes contrários a essas reestruturações.

A variedade de significados atribuídos ao termo "currículo" permitiu Lopes e Macedo (2011) apontarem que ele não é coisa alguma. Entendemos que a "coisa" sinalizada pelas autoras, refere-se ao concreto, inanimado, que pode ser limitadamente definido. Por entenderem currículo, e as tentativas de definições do termo, como uma construção social alocadas em espaços-tempo que precisam compreendidos, destacam as referidas autoras que "a cada uma das tradições curriculares é um discurso que se hegemonizou e que, nesse sentido, construiu o objeto currículo, emprestando-Ihe um sentido próprio" (LOPES; MACEDO, 2011, p.40).

Entendendo que a noção de currículo formal é insuficiente para dar conta da multiplicidade de experiências - internas e externas aos sujeitos, individuais e coletivos - que o compõe, Lopes e Macedo (2011) tecem suas perspectivas sobre currículo como sendo uma prática discursiva, e "isso significa que ele é uma prática de poder, mas também uma prática de significação, de atribuição de sentidos. Ele constrói a realidade, nos governa, constrange nosso comportamento, projeta nossa identidade, tudo isso produzindo sentidos" (LOPES; MACEDO, 2011, p.41).

Diante das compreensões expostas, esclarecemos que corroboramos com os autores acima citados, na medida em que entendemos que currículo se trata de uma construção social e cultural, engendrada por relações de poder que buscam, a todo custo, limitar as ações educacionais e docentes em prescrições documentais. Daí por que entendemos haver uma polissemia de currículos, variando seus sentidos e definições de acordo com determinadas sociedades, aspectos culturais destas, com os sistemas de ensino e os sujeitos que constroem o espaço escolar. 


\section{$O$ percurso da pesquisa}

Referimo-nos a "percurso" tendo em vista que a pesquisa foi se construindo quando de nossa estada em campo, ao longo de todo ano de 2018. Durante este ano construímos os dados da pesquisa por meio de acompanhamentos de aulas, captação de entrevistas, incluindo também as análises desses dados e demais informações coletadas.

Como instrumentos de construção de dados, utilizamos narrativas e acompanhamentos de aulas. O sentido de narrativa tem como referência os estudos de Delory-Momberger (2011), que a considera como um gênero discursivo que promove o encontro com o outro, por meio da experiência de troca da palavra falada. Para esta autora, a narrativa "[...] é também o espaço em que o ser humano se forma, elabora e experimenta a sua história de vida (DELORYMOMBERGER, 2011, p.341).

A captação das narrativas ocorreu por meio de entrevistas, entendidas estas à luz dos estudos de Gil (2008, p.109), como uma "técnica em que o investigador se apresenta frente ao investigado e the formula perguntas, com o objetivo de obter dados que interessam à investigação". Já os acompanhamentos ocorreram durante aulas de Matemática, com os quais buscamos compreender como se dá construção das práticas pedagógicas matemáticas dos professores e as vivências destes com os estudantes no espaço escolar.

Salientamos que os primeiros contatos com a escola pesquisada ocorreram através de e-mails, no segundo semestre de 2017. Neste período, a coordenadora pedagógica responsável pelas turmas de EJA nos cedeu uma planilha, na qual encontramos informações referentes aos docentes da modalidade. Dentre as informações, destacamos que a escola pesquisada contava com cinco professoras de EJA, cada uma responsável por uma turma. As docentes mantinham contrato temporário de um ano com Secretaria Municipal de Educação (SEDUC).

Ao final de 2017, os docentes com contrato temporário da SEDUC, passaram por um processo seletivo de provas e títulos. Entre os aprovados nesta seleção, apenas duas das cinco professoras da EJA da escola pesquisada lograram êxito e, em 2018, mantiveram-se na escola e nas turmas de EJA de mesma nomenclatura do anterior: turma EJA " $A$ " e turma EJA " $B$ ". Assim, definimos que seriam estas duas as participantes de nossa pesquisa, pois, em tese, elas seriam mais experientes na escola pesquisada. 
Ao entrar em contato com estas professoras, no início de 2018, elas aceitaram ceder entrevistas e serem acompanhadas. As entrevistas aqui apresentadas ocorreram em fevereiro do referido ano, já os acompanhamentos analisados ocorreram nas aulas de Matemática durante o mês de março de 2018.

Ao realizarmos as leituras das narrativas destas duas docentes, estabelecemos aproximações entre os materiais dos acompanhamentos, nossas interpretações enquanto pesquisadores e as analisamos de acordo com aporte teórico sobre currículos. Antes, porém, de adentrarmos em discutir sobre os resultados da pesquisa, esclarecemos os perfis das professoras e das turmas de EJA acompanhadas.

\section{Os perfis das docentes}

Nesta seção apresentamos as professoras informantes-chaves e as turmas que foram o lócus de nosso estudo. Prezando pelas identidades das docentes, optamos por nos referirmos às mesmas pelos nomes fictícios de Laura e Maria.

Laura tem 25 anos de idade, é solteira e mora no Distrito onde a escola pesquisada situa-se. Sua escolarização na Educação Básica se deu em escolas públicas. Possui graduação em Ciências Biológicas e, até fevereiro de 2018, ela estava cursando uma pós-graduação lato sensu, direcionada para o ensino de Biologia. Lecionava há 3 anos em escolas públicas, por meio de contrato temporário. Quando de nossa entrevista, ela encontrava-se ensinando Biologia em uma escola Estadual de Ensino Médio, na periferia da cidade, nos turnos manhã e tarde; no turno da noite, lecionava em uma turma de EJA, em uma escola pública municipal no distrito da zona rural. A mesma informou não possuir cursos direcionados à EJA, participando apenas dos momentos de estudos nas formações de professores, ofertadas pela SEDUC, e dos planejamentos pedagógicos que aconteciam na escola municipal.

Maria tem 60 anos, é casada, mãe de dois filhos e mora na cidade. Sua escolarização na Educação Básica ocorreu em uma escola privada religiosa e em uma escola púbica estadual. A mesma cursou Licenciatura em História, sendo especialista em Metodologia do Ensino Fundamental e Médio. Não possui qualquer curso na área da EJA e sua experiência de vinte anos de magistério divide-se entre Educação Infantil e Ensino Fundamental. É professora 
efetiva da rede de ensino do município lócus da pesquisa, e há seis meses encontra-se lecionando em uma turma de EJA na mesma escola pública municipal no distrito da zona rural onde Laura leciona.

Salientamos que Laura e Maria, mesmo tendo formações acadêmicas em cursos específicos, desenvolvem a função de professoras polivalentes, lecionando todas as disciplinas escolares em suas turmas de EJA, além de serem professoras alfabetizadoras. Alguns docentes, como é o caso de Laura, desenvolvem ainda a função administrativa de ser responsável pelo edifício anexo em que funciona sua turma.

\section{As turmas de EJA acompanhadas}

O lócus de nossa pesquisa foram duas turmas de EJA de uma escola pública municipal, localizada em um Distrito da zona rural de Sobral, cidade do interior do Ceará. Esta escola contempla as etapas Educação Infantil, anos iniciais e anos finais do Ensino Fundamental nos turnos diurnos e EJA, no noturno. Possui quatro edifícios anexos, que ficam situados, cada um, em localidades rurais mais distantes da sede do Distrito, nos quais funcionam as turmas de jovens, adultos e idosos.

De acordo com a plataforma QEdu ${ }^{5}$, em 2018, ano de nossa estada em campo construindo dados, a escola pesquisada contou com 131 estudantes matriculados na EJA, organizados em 5 turmas. Sinalizamos que as turmas de EJA da escola pesquisada são do tipo multisseriadas, isto é, são formadas por estudantes dos níveis de EJA I, EJA II, EJA III e EJA IV6, organizados em uma mesma sala de aula.

Neste artigo, analisaremos as turmas multisseriadas "EJA A" e "EJA B". A primeira funciona em um prédio Anexo $A$, distante $1 \mathrm{~km}$ da sede do Distrito, e tem Laura como professora responsável. Este Anexo A é formado por 3 salas de aula, 1 sala dos professores,1 sala de coordenação pedagógica, 1 cozinha, 1 depósito despensa, 1 depósito de materiais

\footnotetext{
${ }^{5}$ O QEdu trata-se de uma plataforma online que dispõe de informações e dados educacionais. Disponível em: https://www.qedu.org.br/. Acesso em 14 jan. 2020.

${ }^{6}$ O nível EJA I contempla o 1으, o 2ำ e 30 ano dos anos iniciais do Ensino Fundamental Inicial. O nível EJA II corresponde

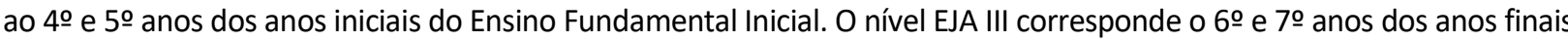
do Ensino Fundamental. O nível de EJA IV contempla o 8ㅇ e 9o anos dos anos finais do Ensino Fundamental.
}

Periódico Horizontes - USF - Itatiba, SP - Brasil - e020043 
diversos e 4 banheiros. Não possui áreas de lazer ou aberta, nem biblioteca ou sala de leitura.

Na Tabela 1, apresentamos as características dos estudantes dessa turma.

Tabela 1: Perfil da turma multisseriada "EJA A".

\begin{tabular}{ccccc|c|cccc}
\hline \multirow{2}{*}{ Sexo } & \multicolumn{4}{c|}{ Nível de EJA } & \multirow{2}{*}{ Total } & \multicolumn{4}{c}{ Faixa etária } \\
& I & II & III & IV & & $15-30$ & $31-45$ & $46-60$ & $61-75$ \\
\hline Mulher & 1 & 4 & 1 & 1 & 7 & 1 & 3 & 3 & 0 \\
Homem & 3 & 1 & 4 & 9 & 17 & 4 & 5 & 7 & 1 \\
\hline Total & 4 & 5 & 5 & 10 & 24 & 5 & 8 & 10 & 1 \\
\hline \multicolumn{4}{c}{ Fonte: Dados codificados pelos pesquisadores. }
\end{tabular}

A leitura dos dados acima nos permite compreender que a turma EJA A é composta de 17 estudantes homens. Estes concentram-se na faixa etária entre 46 e 60 anos de idade, e boa parte deles estavam nos níveis de EJA IV, ou seja, estariam concluindo seus estudos nos anos finais do Ensino Fundamental, em 2018. As mulheres, por sua vez, concentram-se na faixa etária entre 31 e 60 anos de idade, e estavam 4 destas, no nível de EJA II, ou seja, finalizando seus estudos nas séries iniciais do Ensino Fundamental.

A turma EJA B funciona em um prédio Anexo $B$, distante $7 \mathrm{~km}$ da sede do Distrito, e tem Maria como professora responsável. Este prédio é composto por 3 salas de aulas, 1 cozinha, 1 depósito despensa e 2 banheiros. Não possui áreas de lazer ou aberta, nem biblioteca ou sala de leitura. Na Tabela 2 apresentamos as características dos estudantes dessa turma.

Tabela 2: Perfil da turma multisseriada "EJA B".

\begin{tabular}{|c|c|c|c|c|c|c|c|c|c|}
\hline \multirow{2}{*}{ Sexo } & \multicolumn{4}{|c|}{ Nível de EJA } & \multirow{2}{*}{ Total } & \multicolumn{4}{|c|}{ Faixa etária } \\
\hline & I & II & III & IV & & $15-30$ & $31-45$ & $46-60$ & $61-75$ \\
\hline Mulher & 3 & 4 & 2 & 5 & 14 & 1 & 6 & 7 & 0 \\
\hline Homem & 3 & 5 & 3 & 3 & 14 & 4 & 6 & 4 & 0 \\
\hline Total & 6 & 9 & 5 & 8 & 28 & 5 & 12 & 11 & 0 \\
\hline
\end{tabular}

Os dados acima demonstram que a turma EJA B possui equidade entre as quantidades de estudantes homem e mulher. Os homens concentram-se na faixa etária entre 31 e 45 anos de idade, e no nível de EJA II, ou seja, estariam, alguns destes, concluindo as séries que compõem os anos iniciais do Ensino Fundamental, em 2018. As mulheres concentram-se na 
faixa etária entre 46 e 60 anos de idade e, por sua vez, estavam 7 delas, no nível de EJA IV, concluindo as séries que compõem os anos finais do Ensino Fundamental, em 2018.

Ao analisar e comparar as duas turmas, é possível perceber diferenças entre elas, seja em relação às idades dos estudantes, a quantidade de homens ou mulheres nela matriculados, além dos níveis de EJA em que estes se encontram. Reconhecemos estas diferenças como características, de uma forma geral, de turmas de jovens, adultos e idosos. Acreditamos que elas podem incidir diretamente nas diferentes maneiras que as professoras constroem suas práticas curriculares e nas formas como as mesmas lidam com os estudantes em sala de aula.

\section{As práticas curriculares matemáticas}

Nesta seção apresentamos os resultados de nossa pesquisa, sobre os quais encaminhamos algumas discussões. Esclarecemos que o sentido de práticas curriculares é considerado sob o entendimento de currículo como uma construção discursiva, em que estão trançadas as práticas pedagógicas dos professores, as realidades dos contextos das vivências e saberes dos estudantes, e as relações construídas nos espaços escolares. Por focarmos nos momentos de acompanhamentos em aulas da disciplina Matemática, é que enfatizamos estas práticas curriculares como matemáticas.

Primeiramente lançamos um olhar sobre os sentidos de currículos que podem ser percebidos a partir das narrativas das docentes. Em seguida, encaminhamos discussões sobre as vivências matemáticas em sala de aula, em que as professoras executaram suas práticas pedagógicas.

\section{Um olhar sobre os sentidos de currículos nas narrativas das docentes}

Os encontros com as professoras Laura e Maria foram realizados em fevereiro de 2018, ocasião em que as entrevistamos. Tais encontros possibilitaram ricos diálogos, além de permitir o reconhecimento das suas condições de mulheres professoras. Nesta subseção apresentamos e analisamos as narrativas destas professoras norteadas pela pergunta: Como você elabora suas aulas para a turma de EJA? 
Com Laura obtivemos o seguinte diálogo:

Laura: - Eu separo por etapa. Aquele aluno que não está sabendo, eu tenho aquele zelo, aquele cuidado de ficar na base e tentar fazer o possível, brincando, mostrando figurinhas, joguinhos, letrinhas, para ele se desenvolver. Eu tenho que adaptar, né. Eu também conto com a ajuda das formações de professores. Lá a gente aprende muita coisa interessante, tem atividades bem legais e dinâmicas também, e a gente pode trazer para sala de aula, colocar em prática com os alunos, só precisar trazer para realidade deles, adaptar. Lá os formadores nos deixam mais seguros, mostram como a gente deve passar para os alunos. Eles dão direcionamento para que a gente possa trabalhar com segurança em sala de aula, como deve fazer as tarefas mais próximas da realidade dos alunos. A gente já sai de lá prontinha para ir para sala de aula, com as atividades, o currículo do mês, os conteúdos, o que deve ser passado para os alunos. É tudo organizado. E a gente tem que usar o livro didático, né, senão a coordenadora pega no pé. Ela também ajuda bastante, tem os planejamentos pedagógicos, a gente conversa como devem ser as aulas, que material utilizar, como proceder em nossa prática em sala de aula. Mas muita coisa eu sei que os alunos não dão conta. Eles sabem pouco. Então, do que eu pego na formação de professores e no planejamento pedagógico, eu tenho que ir peneirando o que é melhor e mais fácil para eles aprenderem. Então, assim, do que eu aprendo na formação de professores, eu passo o que é mais viável, mais fácil mesmo, bem rasteiro, sabe. A gente tem que adaptar mesmo, pegar uma coisinha daqui, outra dali, pegar um dever do livro e vai fazendo atividades diferentes. Tem que ser lúdico, dinâmico, nada de coisa parada também, senão eles ficam cansados. Mas assim, sempre que posso eu pego coisas diferentes, atividades diferentes, é uma brincadeira, uma advinha, um ditado, uma conta mais fácil, tudo de acordo com os conhecimentos deles, tudo adaptado. Até as atividades, quando não tem xerocadas, eu tenho que ser criativa na hora sabe, sem eles perceberem. E nem adianta dizer que tenho que dar conta disso, daquilo, de divisão, sem eles saber ao menos a subtração. É trabalhar com tampinha de garrafa, com jogos lúdicos. Isso eles ensinam na formação de professores e a coordenadora fala, mas tem coisa que ainda é difícil para os alunos. Então eu não ensino do jeito que é dado na formação de professores, do jeito que eles querem. Eu escuto, vou lá, aprendo, escuto a coordenadora, mas no final, eu sei a realidade da turma. E assim eu vou fazendo minhas aulas e já faz seis meses que estou na EJA e estou adorando.

Destacamos as palavras "formação de professores", "planejamento pedagógico", "direcionamento", que poderíamos resumir a fala da professora Laura, quando esta nos informa sobre como elabora suas aulas na EJA. São palavras interligadas que permitem uma primeira análise de que a ação da professora é encaminhada por uma padronização de prática pedagógica, proposta nos momentos de estudos na formação de professores e nos planejamentos pedagógicos. 
Esta padronização pode ser resultante de um sentido de currículo enquanto documento prescrito (SACRISTÁN, 2000) que busca legitimar um saber conteudista como aquele que deve ser "transmitido" na sala de aula, e como o professor deve proceder em sala de aula. Encontramos esse sentido de "currículo" expressamente esclarecido no objetivo do documento Plano Estratégico da EJA (PEEJA) que organiza a estrutura curricular e o ensino das turmas de EJA das escolas públicas municipais de Sobral: é "nortear, orientar e propor ações, estratégias e metas que deverão ser perseguidas cronologicamente" (SOBRAL, 2005, p.3).

Dois recortes sobre estes momentos de estudos merecem destaque na fala da professora Laura, são eles: (1) "A gente já sai de lá prontinha para ir para sala de aula, com as atividades, o currículo do mês, os conteúdos, o que deve ser passado para os alunos. É tudo organizado" e (2) "Então eu não ensino do jeito que é dado na formação de professores, do jeito que eles querem. Eu escuto, vou lá, aprendo, escuto a coordenadora, mas no final, eu sei a realidade da turma".

Acreditamos que a fala (1) traz uma narrativa que parece mostrar uma visão positiva da professora sobre como acontecem os momentos de formação de professores, de onde os docentes saem "prontinhos" para dar aula na EJA, inclusive comum "currículo do mês", como ela diz. Contudo, em (2), Laura nos informa que "não" ensina do jeito que eles querem, referindo-se aos formadores e a coordenadora; o que nos permite um primeiro entendimento de ser a professora resistente às prescrições. Mas quando esta nos diz: "A gente tem que adaptar mesmo, pegar uma coisinha daqui, outra dali, pegar uma dever do livro e vai fazendo atividades diferentes", mostra que a professora realiza o que Goodson (2015) chama de relação de cumplicidade: ela reconhece o poder de controle das prescrições curriculares, mas, ao mesmo tempo, cria suas artimanhas didáticas em sala de aula.

A palavra "adaptar" e suas derivações também são emergentes na fala da professora Laura. Elas aparecem pelo menos três vezes: "[...] só precisar trazer para realidade deles, adaptar", "[...] Eu tenho que adaptar, né" e "[...] tudo de acordo com os conhecimentos deles, tudo adaptado". Em todas elas, "adaptar" faz referência a uma possível transformação do que é proposto como atividades e conteúdos, às vivências dos estudantes da EJA. Este sentido de "adaptação" suscita pelo menos duas interpretações: I) a professora é consciente das especificidades dos estudantes, e II) a professora constrói sua prática curricular com um 
sentido próprio que se aproxima das realidades e especificidades dos estudantes e, de certa maneira, distanciando-se da padronização proposta.

Entendemos como desejável esta ação da professora Laura em adaptar, ou "peneirar" as atividades dos estudantes de acordo com os níveis de aprendizagem de cada um, na tentativa também de complementar o material orientado pela formação de professores e planejamentos pedagógicos. Entretanto, ressaltamos que é preciso haver um cuidado nesta adaptação, no sentido de, enquanto professores, não cairmos em truísmos de que qualquer tipo de atividade contribui para a aprendizagem dos estudantes; de que, ao desenvolver práticas infantilizadas do tipo "brincando, mostrando figurinhas, joguinhos, letrinhas" ou "uma advinha, um ditado", uma conta mais fácil, ainda que supostamente esteja "tudo de acordo com os conhecimentos" dos estudantes, estaremos contribuindo para a formação de um cidadão crítico. Cabe-nos estar cientes de que a lida com o público de jovens, adultos e idosos, que estão em turmas de EJA, exige que o professor jamais seja um profissional "aligeirado ou motivado apenas pela boa vontade ou por um voluntariado idealista e sim um docente que se nutra do geral e também das especificidades que a habilitação como formação sistemática requer" (BRASIL, 2000, p.56).

Compreendemos que, mesmo com uma prática curricular que pode ser entendida como inadequada à faixa etária do público da EJA, a professora Laura, dentro do seu limite didático e pedagógico, tenta acompanhar as realidades da sua turma. É possível que este limite esteja influenciado pela pouca experiência na EJA, como ela nos disse: "já faz um seis meses que estou na EJA e estou adorando", e mesmo pela sua formação acadêmica ser de uma área diferente da Matemática. Esta última situação é um ponto que sinalizamos como de contribuição para os constantes equívocos do ensino dos saberes escolares matemáticos aos estudantes da EJA.

As motivações que levam a professora Laura "adaptar" o que é proposto nos momentos de formação de professores e nos planejamentos pedagógicos, ao que ela entender ser os níveis de conhecimentos dos estudantes, demonstra um distanciamento, até certo ponto, das prescrições curriculares. Esta distância é por nós entendida como positiva, retrata o momento em que permite Laura expressar os saberes didáticos apreendidos em sua formação acadêmica, sua criatividade, e que ela enuncia um sentido de currículo que considera mais os 
saberes dos estudantes, em detrimento do "currículo do mês".

Nosso encontro com a professora Maria também encaminhou um rico diálogo, a partir do qual tomamos conhecimento das estratégias didáticas e de como ela constrói suas práticas na sala de aula de EJA. Perguntamos a mesma: Como você elabora suas aulas para as turmas de $E J A$ ?

Maria: - Então, a partir do material que a gente recebia na formação de professores e do livro que a gente tinha, a gente começava a pensar, a trabalhar aquele conteúdo na sala de aula. Geralmente eu pegava muitas atividades na internet, imprimia e levava; por exemplo, a questão de conjunto, a quantidade de coisas que tinha ali, a multiplicação. O meu EJA II pegava a mesma multiplicação da EJA IV, as contas simples eles pegavam. Então eu conseguia trabalhar a Matemática em geral assim. Isso daí veio lá da formação de professores, porque a gente vê relatos, na nossa formação da EJA, que ajuda bastante e a gente tinha as atividades que já vinham de acordo com a necessidade de nossos alunos. Lá na formação eram divididos os professores formadores de cada disciplina e a partir daí eles trabalhavam os temas, porque era uma turma mista de EJA e eram muitas atividades que vinha de cada segmento. Eles dividiam direitinho o tempo e tentavam passar como a gente deveria passar para os estudantes, mas é claro que só a gente sabia da vivência e da realidade. Tinha o tempo da Matemática, do Português, da História, e das outras matérias da EJA. Do livro eu utilizava as partes mais fáceis, e o que a coordenadora indicava. Eu procurava a partezinha mais fácil, e não dava para fazer as atividades. Os planejamentos pedagógicos também ajudavam bastante. A gente se reunia com a coordenadora todo mês, tinha os encaminhamentos das aulas, dos conteúdos, de como deveriam ser avaliados os alunos todo mês. Tinha atividades também que a gente elaborava em conjunto. Eu sempre procurei adaptar tudo aos conhecimentos dos estudantes, à realidade da minha turma. De que adianta eu colocar um assunto difícil, só por que veio na formação de professores ou a coordenadora disse que é para fazer, por que tem no livro, se eu sei que eles vão ter dificuldades. Se eu fizer isso eles nem vêm mais para aula.

"Conteúdos", "planejamentos pedagógicos" e "formação de professores" são também algumas palavras emergentes na narrativa de Maria. Quando esta nos informa que na formação de professores, os formadores "dividiam direitinho o tempo e tentavam passar como a gente deveria passar para os estudantes, mas é claro que só a gente sabia da vivência e da realidade", compreendemos que estes momentos se tratavam de um espaço onde os professores iriam "aprender" como ensinar aos estudantes da EJA.

A divisão do tempo nas formações de professores relacionava-se às disciplinas 
escolares, como a professora relata: "Tinha o tempo da Matemática, do Português, da História, e das outras matérias da EJA". É possível que esta organização buscasse representar os tempos de aulas de cada disciplina nas turmas de EJA. Ao nos dizer que lá, os formadores "tentavam passar como a gente deveria passar para os estudantes", Maria confirma nossa concepção de nos momentos de formações de professores direcionava-se um sentido de padronização das práticas pedagógicas destes, para que todos "devessem" ensinar igual, ou pelo menos parecido, os "conteúdos" do "currículo do mês", sinalizados por Laura.

No que diz respeito aos planejamentos pedagógicos, destacamos a seguinte fala de Maria: “Os planejamentos pedagógicos também ajudavam bastante. A gente se reunia com a coordenadora todo mês, tinha os encaminhamentos das aulas, dos conteúdos, de como deveriam ser avaliados os alunos todo mês. Tinha atividades também que a gente elaborava em conjunto". Entendemos que o "a gente se reunia", refere-se à Maria com as demais professoras - incluindo Laura - e a coordenadora das turmas de EJA. Neste recorte de fala percebemos que os "encaminhamentos" propostos pela coordenadora, assim como aqueles propostos pelos formadores, orientam para que as professoras construam uma mesma prática curricular, ainda que trabalhem em turmas diferentes.

Reiteramos que a proposta de "padronização" tem como base o PEEJA (SOBRAL, 2005), no qual destaca-se no tópico 14: “O que almejamos com a formação humana e capacitação técnica dos/as professores/as da EJA" (p.25). Esta "formação humana e capacitação técnica" citados acima são compreendidas quando, no referido documento, especifica-se:

Definindo-se a primeira (formação): treinar as emoções e o entendimento do professor ou da professora, de modo que possa sempre se relacionar com seus alunos e alunas na biologia do amor (respeito mútuo) e interagir com eles e elas sem censurar a sua maneira de ser. A segunda (capacitação) visa criar um espaço de conhecimentos reflexivos e de capacidades de ação no professor ou na professora, para que possam guiar seus alunos e alunas na contínua ampliação dos conhecimentos reflexivos e da capacidade de ação, apenas corrigindo o seu fazer e não o seu ser (SOBRAL, 2005, p.26).

Contudo, a fala de Maria, quando esta nos diz: “[...] mas é claro que só a gente sabia da vivência e da realidade", aponta para o entendimento de que ela constrói suas maneiras e formas didáticas próprias de lecionar e lidar com as especificidades dos estudantes de sua 
turma. Estas formas próprias de lecionar também partem de "adaptações" dos materiais cedidos nas formações de professores e elaborados pelas docentes nos planejamentos pedagógicos. A professora explicita esta nossa compreensão quando nos informa: "Eu sempre procurei adaptar tudo aos conhecimentos dos estudantes, a realidade da minha turma. De que adianta eu colocar um assunto difícil, só por que veio na formação de professores ou a coordenadora disse que é para fazer, por que tem no livro, se eu sei que eles vão ter dificuldades".

Entendemos, assim, que a professora Maria enuncia um sentido de currículo que busca contemplar as especificidades dos estudantes da EJA, ao mesmo tempo, não abre mão dos conteúdos escolares, procurando construir maneiras didáticas de contemplá-los em suas aulas. Decerto que, mesmo fazendo suas adaptações, ainda haverá um jogo de tensões entre as forças de controle no "dar conta" dos conteúdos escolares e resistências das professoras em fazer de seus modos, o que elas consideram ser mais próximo das vivências dos estudantes.

As falas das duas docentes encaminham à compreensão de que elas reconhecem as contribuições dos estudos nos momentos de formação de professores e planejamentos pedagógicos para a construção de suas práticas pedagógicas matemáticas. Ao mesmo tempo, sinalizam que, os ensinamentos e materiais construídos nestes momentos de estudos, ainda que elaborados coletivamente, precisam ser adaptados às especificidades de suas turmas e à realidade da zona rural. Estas práticas serão melhor percebidas na seção seguinte, em que lançamos um olhar sobre as observações e acompanhamentos nas salas de aulas.

Reconhecemos que Maria e Laura são agentes construtoras de currículos em suas aulas, em suas experiências profissionais. Suas narrativas são tecidas pelo envolvimento com a educação, o respeito à diversidade dos estudantes da EJA e pela valorização das diferenças destes sujeitos. Além de nos permitirem perceber que suas práticas curriculares matemáticas se encontram nas tensões entre um sentido de currículo prescrito (SACRISTÁN, 2000) que valoriza a aquisição dos saberes escolares, e um que, não abrindo mão destes, em contrapartida, considera mais os saberes dos estudantes. Seguindo na contramão das padronizações propostas, reconhecemos que as docentes assumem um papel significativo na construção de práticas que possibilitam o reconhecimento e valorização das especificidades dos saberes dos estudantes. 
A ação de ouvir Laura e Maria nos permitiu emergir em discussões densas, tensas e complexas, que são as pertinentes do campo do currículo, sobretudo por que trançadas às experiências de professoras, mulheres, vozes que falam e vivenciam a EJA, trazem à tona aspectos poucos conhecidos da educação voltada para jovens, adultos e idosos estudantes dessa modalidade da Educação Básica historicamente pouco valorizada.

\section{Um olhar sobre as vivências matemáticas em sala de aula}

Nesta seção trazemos algumas discussões sobre os acompanhamentos de aulas de Matemática ${ }^{7}$, realizados nas turmas das professoras Laura e Maria. Para fins deste artigo, discorremos sobre as observações realizadas em março de 2018 , com os quais objetivamos compreender como se deu a construção das práticas pedagógicas matemáticas destas docentes e as suas vivências com os estudantes no espaço escolar.

A professora Laura é responsável pela turma EJA A e a professora Maria é responsável pela turma EJA B. As principais informações dos acompanhamentos estão destacadas nos Quadros que se seguem, sobre os quais tecemos nossas discussões.

Quadro 1. Acompanhamentos da turma EJA A.

\begin{tabular}{|c|c|l|l|}
\hline Dia & Temática & \multicolumn{1}{|c|}{ Procedimentos didáticos } & \multicolumn{1}{c|}{ Atividade } \\
\hline 06/03 & $\begin{array}{c}\text { Adição e } \\
\text { subtração de } \\
\text { números } \\
\text { naturais }\end{array}$ & $\begin{array}{l}\text { Diálogo com estudantes; } \\
\text { Explicações sobre adição e subtração; } \\
\text { Distribuição e correção coletiva da atividade. }\end{array}$ & $\begin{array}{l}\text { Atividade impressa } \\
\text { Soma e Subtração }\end{array}$ \\
\hline $13 / 03$ & $\begin{array}{c}\text { Multiplicação } \\
\text { de números } \\
\text { naturais }\end{array}$ & $\begin{array}{l}\text { Exemplificação de multiplicações; } \\
\text { Distribuição da atividade; } \\
\text { Leitura e correção coletiva. }\end{array}$ & $\begin{array}{l}\text { Atividade impressa } \\
\text { Multiplicação }\end{array}$ \\
\hline $20 / 03$ & Revisão & Distribuição e leitura silenciosa da atividade. & $\begin{array}{l}\text { Atividade impressa } \\
\text { Avaliação }\end{array}$ \\
\hline
\end{tabular}

Fonte: Quadro elaborado pelos pesquisadores.

Durante o mês de março de 2018, as professoras revisaram os conteúdos dos "Números Naturais", razão pela qual, as três primeiras aulas de Laura ressaltaram a apresentação dos

${ }^{7}$ Os acompanhamentos na turma EJA A, ocorreram nos dias de terça-feira, e para a turma EJA B, nos dias de quarta-feira. Tais dias foram assim definidos, pois as aulas de Matemática ocorriam no segundo tempo de aula, de $19 \mathrm{~h} 40 \mathrm{~min}$ às $21 \mathrm{~h} 20 \mathrm{~min}$.

Periódico Horizontes - USF - Itatiba, SP - Brasil - e020043 
numerais, posição destes na reta numérica, e as noções básicas das operações soma e subtração. Para elaboração destas aulas, Laura seguiu a matriz de conteúdo mensal, cedida na formação de professores, realizada em fevereiro de 2018. Ela se refere a essa matriz como sendo o "currículo do mês, os conteúdos, o que deve ser passado para os alunos".

A primeira aula acompanhada na turma EJA A ocorreu no dia 06 de março de 2018. Nesta foi abordado o conteúdo "Adição e subtração de números naturais" e que "seria trabalhado com todos ao mesmo tempo" segundo fala de Laura. Para iniciar a aula, a professora propôs algumas perguntas aos estudantes: "O que é um número natural?" e "Se eu compro uma caneta e depois compro mais duas, eu fico com quantas canetas?". Após isso, ela seguiu explicando no quadro branco duas contas: uma de adição e outra de subtração. A docente repetiu as explicações com outras contas, conforme alguns estudantes perguntavam como se resolvia: "uma de três números agora", "e se fosse mais parcelas". Dadas as explicações, ela distribuiu uma mesma atividade de Matemática impressa, fez uma leitura coletiva e deu "um tempo para responderem os probleminhas de somar e diminuir".

Durante este tempo, percebemos que alguns dos estudantes agruparam-se entre si, formando grupos por proximidades das carteiras. Estes eram, em sua maioria, estudantes dos níveis EJA III e EJA IV, que se ajudavam, tiravam as dúvidas dos outros e eram incentivados pela professora para continuarem agindo desta forma. Outros faziam a atividade individualmente, eram os estudantes dos níveis EJA I e EJA II, que recebiam maior atenção da professora. Para estes, Laura lia e explicava novamente os problemas, mostrava, por exemplo, que sinais deviam ser utilizados, até que os estudantes respondessem sozinhos. Como finalização da aula, a professora corrigiu algumas questões no quadro, instigando a participação dos estudantes por meio de perguntas de como eles chegaram aos seus resultados.

Neste primeiro acompanhamento percebemos que os diálogos que Laura mantinha com os estudantes contribuíam para que eles participassem da aula, expondo suas dificuldades e dúvidas. A mesma incentivava o trabalho em grupo e, pelo percebido, esta estratégia didática também a ajudava na dinâmica da aula, contribuindo para sua assistência aos estudantes.

A docente utilizou uma mesma atividade para toda a turma, tendo em vista que o conteúdo abordado seria trabalhado de maneira igual com todos os estudantes. O que entendemos contribuir também para o desenvolvimento da aula, na medida em que ela 
centraria o debate e explicações sobre questões e assuntos iguais.

A segunda aula acompanhada ocorreu no dia 13 de março de 2018. Nesta foi abordado o conteúdo "Multiplicação de números naturais", conforme Laura iniciou sua fala, antes de prosseguir nas explicações sobre "o que seria multiplicar". A mesma pediu para os estudantes escolherem um número entre 1 e 9, e o escrevesse em uma folha. Diante disso, seguiu indicando: "somem o número escolhido mais ele mesmo", em seguida, "pegue o resultado encontrado e some com um mesmo número". Ao mesmo tempo, Laura construía uma tabela no quadro, demonstrando o que era o dobro e o triplo de alguns números, relacionando à operação adição.

Realizadas estas explicações, Laura agrupou os estudantes em duplas, nas quais, percebemos que a docente optou por direcionar quem ficava com quem. Um estudante ficou sozinho acompanhado da professora, enquanto os demais formaram duplas: um estudante do nível EJA I com um do nível EJA IV, outro do nível EJA II com um do nível EJA III, e assim sucessivamente. Segundo ela, era "para um ajudar o outro". Enquanto os estudantes resolviam a atividade, Laura circulava entre os grupos explicando "a melhor forma de resolver", conforme ouvimos em uma de suas explicações.

Ao longo do tempo em que os estudantes estavam envolvidos em resolver as questões, nos dispomos próximos a uma dupla. Um dos estudantes demonstrou estar compreendendo o que estava sendo proposto nas questões e, em um momento, declarou: "Olha já tô até sabendo. Tá meio complicado, mas a fulana sabe explicar". Percebemos que Laura centrou mais atenção nas duplas em que estavam estudantes do nível EJA I e do nível EJA II, possivelmente por serem estes os que tinham mais dificuldades em Matemática. Esta aula foi encerrada com uma correção coletiva, contando com a participação de uma estudante, que explicou no quadro uma das questões da atividade.

Em um diálogo com Laura, iniciado pelo interesse desta em saber como estávamos seguindo na pesquisa, a mesma declarou estar gostando de lecionar na EJA e que "as atividades em grupo ajudam a eles a se envolver, conversar sobre os erros". Aproveitamos para saber se as atividades propostas por ela eram as mesmas das formações de professores, a docente nos respondeu: "Sim. Mas a gente também elabora umas com a orientação da coordenadora, e até aproveitamos atividades passadas, modifica, coloca em outro nível, vai mesclando. A gente vai adaptando à realidade da EJA". 
Esta fala de Laura nos permite retomar nossa compreensão de que entendemos como positivas as adaptações que ela diz fazer em relação às atividades que lhes são propostas. Contudo, reiteramos ser preciso cuidado para não haver, nesta adaptação, um julgamento preconceituoso da capacidade dos estudantes, aplicando-lhes atividades de níveis mais baixos de conhecimentos, supostamente entendidos como sendo os seus. Ao se referir: "[...] até aproveitamos atividades passadas, modifica, coloca em outro nível, vai mesclando. A gente vai adaptando à realidade EJA", compreendemos um sentido de "modificação" e "adaptação" próximo ao de "complementação" para "uma parte diversificada" (SOBRAL, 2017, p.4) como é sugerido no documento Proposta Curricular da EJA da escola pesquisada, onde podemos ler:

O currículo do ensino fundamental e médio deve ter uma base nacional comum, a ser complementada, em cada sistema de ensino e estabelecimento escolar, por uma parte diversificada, exigida pelas características regionais e locais da sociedade, da cultura, da economia e da clientela (SOBRAL, 2017, p.4).

Entendemos que ao dizer "A gente vai adaptando à realidade EJA", Laura esteja referindo-se ao nível das questões propostas, bem como à realidade cultural dos estudantes. Este nosso entendimento parte de alguns acompanhamentos realizados antes de março, nos quais observamos que Laura busca pelo diálogo com os estudantes, deixando-os à vontade para falarem sobre o que eles sabiam de Matemática, para, então, iniciar a aula.

Em uma análise geral deste segundo acompanhamento, percebemos que Laura segue as orientações de conteúdos e atividades propostas nas formações de professores, assim como também segue as orientações didáticas da coordenadora pedagógica. Contanto, ao propor a formação de duplas, formando-as de acordo com os níveis de EJA, reiteramos que a docente conhece à realidade de sua turma, e apresenta formas próprias de desenvolver o conteúdo matemático envolvendo os estudantes.

O terceiro acompanhamento ocorreu no dia 20 de março de 2018. Neste, Laura iniciou dizendo que seria uma "aula de revisão", e que os estudantes se esforçassem "para responder sozinhos, por que no dia que tiver avaliação é cada um por si". Ela distribuiu uma mesma atividade impressa com algumas "questões com um pouco de tudo, todo assunto trabalhado", conforme ela declarou. A docente pediu para que os estudantes fizessem uma leitura 
silenciosa, buscando entender "o que a questão queria" e "como resolver".

No espaço de explicações entre algumas questões, quando alguns deles mostravam dificuldades, Laura dirigia-se aos estudantes e buscava entender suas dúvidas. Em alguns momentos ela pedia para que eles falassem o que não haviam entendido. Dentre estas falas, destacamos: “Esse negócio ai de posição dos números é o quê na soma?”. Laura compreendeu que o estudante se referia ao valor posicional dos algarismos, e como resposta, the disse: "Serve para colocar os números da mesma posição um embaixo do outro". Uma estudante completou: "É dezena com dezena, unidade com unidade e assim em diante".

A professora aproveitou o momento do diálogo e demonstrou uma questão da atividade que apresentava uma conta de subtração. Esta sequência de leituras, explicações e resoluções individuais, seguiu para todas as questões da atividade, o que levou todo tempo desta terceira aula. Laura finalizou parabenizando os estudantes pelas suas participações.

Nossas interpretações dos acompanhamentos nos encaminham à compreensão de que Laura, ao elaborar suas aulas, objetiva que os estudantes aprendam os conteúdos escolares de Matemática. Esta nossa percepção nos possibilita um primeiro entendimento de que a docente apresenta uma prática pedagógica matemática voltada à aplicação de conteúdos, construindo um sentido de currículo enquanto grade de conteúdos a serem seguidos e avaliados (GOODSON, 2007). Entendemos que este é o sentido explícito de currículo defendido, intencionalmente ou não, pelo sistema público municipal de ensino de Sobral, desde o início dos anos 2000, quando nele se implantou uma cultura de avaliações externas (INEP, 2005).

Entretanto, percebemos haver uma relação de cumplicidade (GOODSON, 2015) entre as práticas curriculares de Laura e as propostas pelo sistema de ensino, na medida em que a docente, preocupada com os conteúdos escolares, utiliza-se de práticas didáticas que levam em consideração o diálogo com os estudantes, a fim de compreender, primeiramente, os saberes de suas vivências. O que reafirma sua fala, quando ela nos disse: "eu não ensino do jeito que é dado na formação de professores, do jeito que eles querem. Eu escuto, vou lá, aprendo, escuto a coordenadora, mas no final, eu sei a realidade da turma".

Encontramos algumas aproximações entre os resultados das vivências da turma EJA A e a turma EJA B. Sobre esta turma, elencamos no Quadro 2 algumas informações, sobre as quais encaminhamos nossas discussões. 
Quadro 2. Acompanhamentos da turma EJA B.

\begin{tabular}{|c|c|l|l|}
\hline Dia & Temática & \multicolumn{1}{|c|}{ Procedimentos didáticos } & \multicolumn{1}{c|}{ Atividade } \\
\hline $07 / 03$ & $\begin{array}{c}\text { Revisão dos } \\
\text { Números } \\
\text { Naturais }\end{array}$ & $\begin{array}{l}\text { Diálogo e explicações sobre os sinais dos } \\
\text { números; Soma e Subtração; } \\
\text { Leitura coletiva da atividade. }\end{array}$ & $\begin{array}{l}\text { Atividade impressa } \\
\text { Soma e Subtração }\end{array}$ \\
\hline $14 / 03$ & $\begin{array}{c}\text { Adição e } \\
\text { multiplicação }\end{array}$ & $\begin{array}{l}\text { Explicações sobre multiplicação, utilizando } \\
\text { tarjetas de cartolina; } \\
\text { Correção coletiva. }\end{array}$ & $\begin{array}{l}\text { Atividade com tarjetas } \\
\text { de cartolina; } \\
\text { Atividade impressa. }\end{array}$ \\
\hline $21 / 03$ & $\begin{array}{l}\text { "Operaçães } \\
\text { matemáticas } \\
\text { do dia a dia" }\end{array}$ & $\begin{array}{l}\text { Dinâmicas para explicar os conteúdos; } \\
\text { Explicação da atividade; } \\
\text { Correção. }\end{array}$ & Atividade impressa \\
\hline
\end{tabular}

Fonte: Quadro elaborado pelos pesquisadores.

A primeira aula de Matemática acompanhada na turma EJA B aconteceu no dia 07 de março de 2018. Nesta, a professora Maria declarou que o assunto seria uma "Revisão", conforme também escreveu no quadro branco. Ao iniciar a aula dialogando com os estudantes, percebemos que o conteúdo a ser abordado seria "Números naturais", especificamente as operações soma e subtração.

Como início das discussões sobre o conteúdo, Maria foi apresentando aos estudantes algumas imagens de algarismos com sinais positivos, negativos e sem sinais, no intuito de explicar o conjunto dos "Números Naturais". Algumas perguntas foram feitas pelos estudantes, dentre estas, destacamos: "Pode somar números com sinal negativo?", "Sem sinal é o quê, já que não tinha mais nem menos?". Conforme iam perguntando, a professora respondia aos estudantes, demonstrando ter domínio do conteúdo.

Realizadas as explicações do assunto, Maria distribuiu uma mesma atividade de Matemática impressa para todos os estudantes e pediu para que estes, junto com ela, fizessem uma leitura coletiva das questões. Ao longo desta leitura, Maria seguia perguntando aos estudantes suas dúvidas e explicando como proceder na resolução dos problemas matemáticos. Após estas explicações, ela sugeriu que os estudantes do nível EJA III e do nível EJA IV se organizassem em pequenos grupos, enquanto ela se agrupava com os estudantes do nível EJA I e do nível EJA II. Percebemos que, ao utilizar a estratégia de divisão de grupos, Maria buscava incentivá-los a ajudarem, ainda que ela tirasse as dúvidas de quem ia ao seu encontro.

Os estudantes mostraram-se interessados na estratégia de grupo proposta na atividade. Percebemos isso quando um deles disse à professora: "Assim junto fica melhor, a gente 
termina logo e sabe como o outro faz também e compara". Uma estudante retrucou: "Compara ou copia?", os estudantes riram e a professora chamou a atenção para que eles buscassem "ler e entender o que cada questão pede, para depois responder sem errar".

Neste primeiro acompanhamento percebemos haver uma boa interação entre estudantes e a professora. Além do que, compreendemos o desdobramento de atenção que Maria precisava ter para dar assistência a todos os estudantes. Segundo ela, "tem que separar assim, por nível, para eles irem se ajudando e fortalecendo a amizade também". A atividade levou todo o tempo da aula, que foi finalizada com Maria passando o gabarito das respostas.

A segunda aula acompanhada aconteceu no dia 14 de março de 2018. Segundo Maria, nesta aula seria abordado "um pouco de adição, mas o foco seria multiplicação. As contas de vezes". Diante disso, ela iniciou a aula escrevendo no quadro os numerais 8,10 e 50, separadamente, e começou um diálogo com os estudantes: "Se eu somar oito mais oito, quanto dá?", "Se eu somar dez, mais dez, mais dez, vai dar quanto?", "Qual a metade de cinquenta?", "O que é a metade de um número?", dentre outras indagações.

Maria seguiu distribuindo entre os estudantes algumas tarjetas preenchidas com alguns numerais em que, do mesmo lado deste eles deveriam colocar o que ela iria orientando: "Todo mundo está com uma tarjeta? Tem um número nela, de lado desse número você vai colocar o dobro dele. Agora nessa outra tarjeta vamos procurar a metade do número que já tem e completar". Ao finalizar esse momento com as tarjetas, Maria explicou o que seria o dobro, triplo e a metade de um número.

Após estas explicações a professora distribuiu uma mesma atividade impressa para os estudantes e sugeriu que eles fossem respondendo "o que desse, que na hora da correção a gente vê as respostas. Pode se juntar em grupos". Os estudantes agruparam-se em pequenas quantidades, outros optaram por ficar sozinhos, enquanto Maria seguia explicando a três estudantes: "estes são da EJA I, que eu te falei", nos disse ela, referindose a uma conversa anterior, na qual ela informou que na turma tinha alguns com mais dificuldades na multiplicação e que, por isso, precisava "fazer algo diferente, uma coisa mais lúdica, sabe".

Nesta segunda aula, foi possível perceber um bom relacionamento entre os estudantes, com destaque para os mais jovens que, pacientemente, ensinavam os mais idosos e aqueles 
que mostravam ter mais dificuldades com a atividade proposta. A aula foi finalizada com Maria respondendo no quadro algumas questões que os estudantes ficaram com mais dificuldades e retomando os exemplos dados na atividade das tarjetas. Ao longo dessa "revisão coletiva", assim denominada por Maria, ela seguiu dando as explicações de como os estudantes que estavam em seu grupo tinham resolvido as questões.

A terceira aula acompanhada aconteceu no dia 21 de março de 2018, tendo como tema "as operações matemáticas do dia a dia", como informou Maria, que optou por iniciar a aula com um diálogo, dispondo os estudantes em círculo. Diante disso, ela propôs algumas perguntas: "Para ir até a escola pólo, você anda quantos metros?", "Saindo daqui para a escola pólo, que pontos principais do Distrito a gente passa?", "Como se escreve essa distância por extenso?", dentre outras perguntas. Os estudantes mostraram-se participativos ao respondêla: "Tem umas cinco, seis léguas", "Passa pela igreja, o posto, a praça, e por aí vai", "A gente pode falar em quilômetros ou só pode ser em metros?", foram algumas das respostas captadas das falas dos estudantes.

Ao concluir esta exposição do assunto, Maria, aproveitando-se dos estudantes em círculos, falou sobre a "localização dos números". Para isso, a mesma numerou cada estudante (de 1 a 14) e explanou sobre "quem está do lado direito e do lado esquerdo de quem" para, então, discorrer sobre "sucessor e antecessor" numérico. Depois deste segundo momento de explicações, ela distribuiu uma mesma atividade para os estudantes e propôs que formassem duplas, "para resolverem um ajudando o outro". A atividade proposta envolvia contas de adição, subtração, com representações de situações envolvendo o sistema monetário, e localização dos numerais, em variados tipos de reta e sequenciações numéricas. Esta aula foi finalizada com um novo diálogo entre professora e estudantes, em que ela buscou saber deles quais as dificuldades em relação às questões.

O acompanhamento nesta terceira aula ratificou nosso entendimento de que, entre Maria e os estudantes da turma EJA B existe uma relação de aproximação e afetividade. Além do que, mesmo os estudantes sabendo das especificidades de cada um, agrupam-se de maneira a se ajudarem na troca de saberes.

No que diz respeito às estratégias didáticas elaboradas por Maria, compreendemos estarem elas articuladas a um sentido de os estudantes aprenderem os conteúdos curriculares, 
mas, ao mesmo tempo, buscando estar mais próximas da realidade da sua turma. Não diferindo, portanto, das estratégias propostas por Laura. O que nos permite entender que, mesmo lecionando em diferentes turmas de EJA, as docentes construíam suas aulas encaminhadas pelos materiais propostos nos momentos de formação de professores e planejamentos pedagógicos.

É possível que a similaridade entre as aulas e práticas das docentes aconteça também por elas lecionarem em uma mesma escola e construírem, juntas com a coordenadora pedagógica, o material a ser abordado ao longo de cada mês. Entretanto, ao nos dizer que precisava "fazer algo diferente, uma coisa mais lúdica, sabe", analisamos uma necessidade de Maria em construir estratégias que fossem não apenas "diferente", como ela chama, mas opostas do que já tinham lhe proposto.

Deste pensamento, resultou a segunda aula, em que Maria trabalhou com as tarjetas, a fim de que os estudantes, a partir dos entendimentos básicos de adição, pudessem apreender a multiplicação. Caracterizamos esta segunda aula como sendo o "algo diferente", a parte "mais lúdica" pode ser entendida como a terceira aula, onde Maria agregou o diálogo às estratégias variadas para explicar sobre valor posicional dos numerais.

Em suma, analisamos que, diferentemente de Laura, Maria encaminha suas práticas curriculares mais no sentido de resistências às prescrições e padronizações propostas nos espaços de formações e professores e planejamentos pedagógicos. Inclusive, reconhecemos como importante a preocupação das docentes, não só para o "dar conta" dos conteúdos, mas em buscar construir estratégias didáticas que os aborde, de acordo que elas entendem ser as realidades de suas turmas de EJA, e as especificidades dos jovens, adultos e idosos que nelas se encontram estudando.

\section{Considerações finais}

Neste artigo discutimos sobre padronização, relações de cumplicidade e movimentos de resistências, percebidas nas práticas curriculares matemáticas de docentes que lecionam para jovens, adultos e idosos, em uma escola pública municipal a zona rural de Sobral, cidade do interior do Estado do Ceará. Para fins de análises, utilizamos das narrativas de duas professoras 
e de dados construídos em acompanhamentos de aulas de Matemática em suas turmas.

Finda as análises, entendemos que no sistema de ensino do referido município, "currículo" trata-se de documento prescrito definidor dos conteúdos escolares e das práticas pedagógicas dos professores. Este sentido é reproduzido nos espaços de formações de professores e planejamentos pedagógicos frequentados pelas docentes, onde é repassado como elas "devem" ensinar em suas turmas.

As narrativas das duas docentes reforçam este sentido de currículo, mas, ao mesmo tempo, sinalizam que elas elaboram práticas didáticas buscando estarem mais próximas das realidades dos estudantes, em detrimento das padronizações que lhes são propostas. Tais práticas foram encaminhadas nos acompanhamentos das aulas de Matemática, onde percebemos que as professoras, aproveitando os materiais elaborados nas formações de professores e planejamentos pedagógicos, constroem suas aulas a partir de dinâmicas, atividades e dos diálogos estabelecidos com os estudantes.

Percebemos assim, haver movimentos de tensões entre as padronizações propostas pelo sistema municipal de ensino, as relações de cumplicidade - na medida em que as docentes reconhecem a importância dos encaminhamentos das práticas propostas nas formações de professores e planejamentos pedagógicos - e movimentos de resistências por parte das docentes, quando estas apontam elaborarem suas próprias estratégias didáticas de acordo com as realidades de suas turmas.

A conclusão deste artigo contribuiu para que nós, enquanto pesquisadores da educação de pessoas jovens, adultas e idosas, melhor compreendêssemos as disputas trançadas "no chão" da sala de aula de EJA. São muitas as tensões e estas se acentuam quando emergimos nas reflexões sobre "o quê ensinar", "o como ensinar" e "o como avaliar" sujeitos que possuem identidades culturais tão específicas. Ela contribuiu também para o reconhecimento das docentes e dos estudantes como potenciais construtores de sentidos de currículos.

\section{Referências}

BRASIL. Conselho Nacional de Educação/ Câmara de Educação Básica. Parecer no 11 de 10 de maio de 2000. Aprova Diretrizes Curriculares Nacionais para a Educação de Jovens e Adultos. Brasília, 2000. Disponível em: http://portal.mec.gov.br/cne/arquivos/pdf/PCB11_2000.pdf. 
Acesso em: 14 jan. 2020.

BIESTA, G. Boa educação na era da mensuração. Trad. Teresa Dia Carneiro. Cadernos de Pesquisa. Fundação Carlos Chagas. Brasília. v.42, n.147, set./dez. 2012, p.808- 825.

DELORY-MOMBERGER, C. Fundamentos epistemológicos da pesquisa biográfica em educação. Educação em Revista, Belo Horizonte, v.27, n.1, p.333-346, 2011.

FREITAS, A. V. Educação matemática e educação de jovens e adultos: estado da arte de publicações em periódicos (2000 a 2010). 2013. 360f. Tese (Doutorado em Educação Matemática) - Pontifícia Universidade Católica de São Paulo, São Paulo, 2013.

GIL, A. C. Métodos e técnicas de pesquisa social. 6.ed. São Paulo: Atlas, 2008.

GOODSON, I. F. Currículo, narrativa e o futuro social. Trad. Eurize C. Pessanha e Marta B. Rahe. Rev. Bras. Educ. v.12. n.35, p.241- 252, maio/ ago. 2007.

GOODSON, I. F. Narrativas em educação: a vida e a voz dos professores. Porto, Portugal: Porto Editora, 2015.

INEP - Instituto Nacional de Estudos e Pesquisas e Pesquisas Educacionais Anísio Teixeira. Vencendo os desafios da aprendizagem nas séries iniciais: a experiência de Sobral/Ce, vol. 1 [Série Projeto Boas Práticas na Educação]. Brasília, 2005.

LOPES, A. C.; MACEDO, E. Teorias de currículo. São Paulo: Cortez, 2011.

SACRISTÁN, J. G. O currículo: uma reflexão sobre a prática. Trad. Ernani F. F. Rosa. 3.ed. Porto Alegre: Artmed, 2000.

SACRISTÁN, J. G. O que significa o currículo? In: SACRISTÁN, J. G. (org.). Saberes e incertezas sobre o currículo. Trad. Alexandre Salvaterra. Porto Alegre: Penso, 2013, p. 16-35.

SOBRAL. Secretaria Municipal de Educação. Plano estratégico da educação de jovens e adultos PEEJA. 2005.

SOBRAL. Escola José Arimateia Alves. Proposta curricular da EJA. 2017.

XAVIER, F. J. R. A influência de práticas pedagógicas matemáticas na EJA sobre a permanência de estudantes da zona rural de Sobral. 2019. 195f. Dissertação (Mestrado em Educação) Universidade Federal Fluminense, Niterói, 2019.

Recebido em fevereiro 2020.

Aprovado em julho 2020.

Periódico Horizontes - USF - Itatiba, SP - Brasil - e020043 